\title{
Joint injection practice variations in pediatric rheumatology - a global survey and call for action
}

\author{
Anita Dhanrajani ${ }^{*}$ (D) and Raju P. Khubchandani ${ }^{2}$
}

\begin{abstract}
Background: Intraarticular injections (IAI) were first reported in adult rheumatology in the 1950s and subsequently gained acceptance as a safe and efficacious treatment in Juvenile idiopathic arthritis (JIA). IAls are now widely performed and recommended as the initial or only treatment of oligoarticular JIA and ancillary treatment of actively inflamed joints in other varieties of JIA. However, the performance of the procedure is currently not guided by standardized recommendations, and several practice variations are observed.

Methods: This worldwide survey of pediatric rheumatologists (with $48.5 \%$ response from Pediatric Rheumatology International Trials Organization [PRINTO and Pediatric Rheumatology Collaborative Study Group [PRCSG] members) captures the differences in pre-procedural, procedural and post-procedural protocols and practices observed across the globe and asks the necessity of developing consensus in this area of Pediatric Rheumatology.

Results: This worldwide survey of Pediatric Rheumatologists had a response rate of just under $50 \%$ and the views of about $42 \%$ who routinely performed the procedure. It captured the differences in IAI protocols and practices observed across the globe. Significant variations in practice were noted in use of Local anesthesia, choice, and dose of therapeutic agent for the intraarticular injection and use of ultrasound to guide injections. While some practice variations may be explained by institutional protocols in different parts of the world, the clinical implications of these are largely unknown and beg the need for further studies.

Conclusions: Given these practice variations, the authors recommend further studies to explore the cost and clinical implications and subsequently work towards developing consensus plans to ensure uniformity in this widely used procedure in Pediatric Rheumatology.
\end{abstract}

Keywords: Arthritis, Juvenile, Injections, Intra-articular, Surveys and questionnaires

\section{Background}

Intraarticular injections (IAIs) are a common practice in Pediatric Rheumatology, specifically for the treatment of Juvenile idiopathic arthritis (JIA). The earliest published study on IAI use in pediatrics comes from Petty et al. in

\footnotetext{
* Correspondence: anitadhanrajani@gmail.com

This work was conceived and designed when both authors were associated at Jaslok Hospital and Research Center, Mumbai.

${ }^{1}$ Hospital for Sick Children, 8253, Burton Wing, 555 University Avenue, Toronto, ON M5G 1X8, Canada

Full list of author information is available at the end of the article
}

1986 [1], although there are anecdotal reports of pediatric joint injections predating this [2]. Currently, IAI is an accepted initial primary or supplemental tool in management of chronic arthritis in children. The use of glucocorticoid IAI in newly diagnosed oligoarticular JIA is recommended as the initial therapy in the American College of Rheumatology (ACR) Recommendations for the Treatment of JIA: 2011, irrespective of disease activity and prognostic factors [3].

(c) The Author(s). 2020 Open Access This article is licensed under a Creative Commons Attribution 4.0 International License, which permits use, sharing, adaptation, distribution and reproduction in any medium or format, as long as you give appropriate credit to the original author(s) and the source, provide a link to the Creative Commons licence, and indicate if changes were made. The images or other third party material in this article are included in the article's Creative Commons. licence, unless indicated otherwise in a credit line to the material. If material is not included in the article's Creative Commons licence and your intended use is not permitted by statutory regulation or exceeds the permitted use, you will need to obtain permission directly from the copyright holder. To view a copy of this licence, visit http://creativecommons.org/licenses/by/4.0/ The Creative Commons Public Domain Dedication waiver (http://creativecommons.org/publicdomain/zero/1.0/) applies to the data made available in this article, unless otherwise stated in a credit line to the data. 
Several studies, including a systematic review and meta-analysis have clearly established the superior efficacy of Triamcinolone hexacetonide (TH) over Triamcinolone acetonide (TA) in equivalent doses in pediatric IAIs [4-6]. Despite this, TH continues to be unavailable in several countries and innovative methods of procuring it have been reported [7].

Despite the wide use of this procedure in chronic arthritis in children, there are no standard recommendations or guidelines on IAI practices in Pediatric Rheumatology.

In the absence of recommendations to guide IAIs, it is likely that several variations exist in the practice worldwide. The aim of this study was to capture these variations with a web-based questionnaire distributed to members of two major scientific communities - Pediatric Rheumatology International Trials Organization [PRINTO] in the European continent, and Pediatric Rheumatology Collaborative Study Group [PRCSG] in North America, whose membership additionally spans across other continents.

The objectives of the survey were to collect information regarding IAI protocols and practices and to explore the relationship of potential variation with physician demographic features. The ultimate aim is to bring attention to the worldwide variations in practices of this extremely common procedure, to encourage further studies to establish the clinical implications of these variations and work towards developing a set of global recommendations for IAI.

\section{Methods}

\section{Questionnaire design}

A 22-item questionnaire comprising three main sections was designed. Section A pertained to questions regarding procedural variations with respect to: setting of joint injection, number of joints injected, use of ultrasound guidance, choice and dose of therapeutic agent, availability of $\mathrm{TH}$, anesthesia preferences, complications, techniques for prevention of complications, and post procedure practices. Section B addressed variations in practice for patients less than 5 years of age, and Section $C$ was focused on physician demographic characteristics. The questionnaire was pilot tested by 3 pediatric rheumatologists prior to dissemination. The survey was created and disseminated using the web-based platform Survey Monkey. Ethics approval was obtained from Ethics Committee of Jaslok Hospital and Research Center, Mumbai, India.

\section{Subject selection}

The survey link was disseminated via email to: PRCSG $(n=169)$, and PRINTO/PRES members $(n=568)$. The survey was live for 8 weeks with one email reminder sent at the end of week 4 .

\section{Statistical analysis}

Descriptive data are presented as frequencies. Associations between two variables was calculated using chisquare test or Fisher's exact test. Graphpad Prism version 6.01 was used for data analysis.

\section{Results \\ Responses}

The overall response rate was 48.5\% (358/737). 310/358 respondents $(87 \%)$ routinely performed IAI in their clinical practice. The remaining 48 responses were excluded from the analysis as they did not perform IAI routinely. Thus, of the 737 members, 310 responses were captured in this survey $(42.1 \%)$.

\section{Demographics of respondents}

The survey was distributed electronically to members of PRCSG and PRINTO groups with the aim to cover a wide geographical distribution. Table 1 provides baseline information about respondents and Fig. 1 shows the wide geographical distribution of the respondents. 195/ 327 respondents were formally trained in IAI. Other demographics such as age of the respondent, qualifications and credentials were not collected.

\section{Setting of IAI and use of anesthesia}

Majority of the respondents indicated that the procedure was performed in an outpatient setting. $8 \%$ of respondents chose "other" which was further elaborated in comments as "setting differed based on the age of the patient and/or number of joints".

Local anesthesia was the most popular choice amongst respondents (68\%) and Eutectic Mixture of Local Anesthetics (EMLA cream) was the most used local anesthetic agent (39\%). Use of sedation and anesthesia is depicted in Table 2. 22/87 respondents that indicated "other" mentioned the use of Nitrous oxide gas combined with oxygen for sedation in IAI.

\section{Number of joints injected and use of ultrasound}

$79.7 \%$ of respondents inject multiple joints in one sitting; the median number of joints injected per sitting was 4 (range 2-45). Data regarding use of ultrasound in general and for specific joints is presented in Table 3

Table 1 Demographic characteristics of respondents

\begin{tabular}{lll}
\hline & \multicolumn{2}{l}{$\begin{array}{l}\text { Total respondents: } 318^{\mathrm{a}} \\
\mathrm{N}(\%)\end{array}$} \\
\hline $\begin{array}{l}\text { Number of years in } \\
\text { Pediatric Rheumatology }\end{array}$ & $0-5$ years & $31(9.8)$ \\
clinical practice & $5-10$ years & $68(21.4)$ \\
& $10-15$ years & $66(20.8)$ \\
& $>15$ years & $153(48.1)$ \\
\hline
\end{tabular}

${ }^{a}$ Demographics were collected for all respondents 


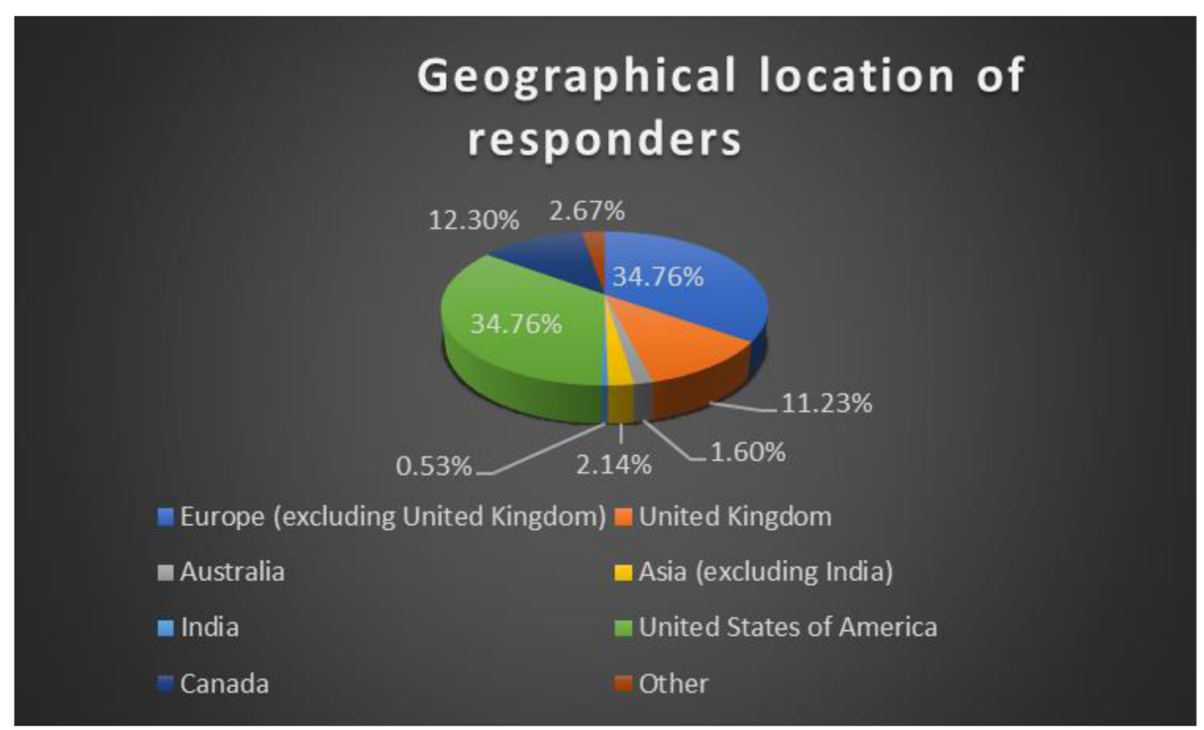

Fig. 1 Geographical location of responders

\section{Therapeutic agent and dose}

Ignoring availability, the medication of choice for IAIs was $\mathrm{TH}$. However, more than $50 \%$ respondents reported that $\mathrm{TH}$ was either not available $(41.9 \%)$ or sporadically available $(9.51 \%)$ in their country. Table 4 depicts frequency of use of different therapeutic agents.

Whereas most respondents indicated use of an alternative agent if $\mathrm{TH}$ was unavailable, several free text comments (Fig. 2) indicated that non-availability of $\mathrm{TH}$ is perceived as a significant barrier.

\section{Dose of steroid in TH equivalent}

The most commonly used dose of steroid ( $\mathrm{TH}$ equivalent) for large and small joint injections was $1 \mathrm{mg} / \mathrm{kg}$ and $0.5 \mathrm{mg} / \mathrm{kg}$, respectively $(n=180$ [64\%] and $n=155$ [55\%], respectively) (Table 5).

\section{Complications and monitoring}

Complications reported by respondents are detailed in Table 6. The most reported complication was subcutaneous atrophy due to leaking of the therapeutic agent

Table 2 IAl setting and sedation

\begin{tabular}{|c|c|c|c|}
\hline \multicolumn{2}{|c|}{ Use of sedation $n(\%)$} & \multicolumn{2}{|l|}{ Setting of IAI n (\%) } \\
\hline Oral sedation & $52(18.4)$ & $\begin{array}{l}\text { Outpatient/Procedure } \\
\text { room }\end{array}$ & $159(52.8)$ \\
\hline Short anesthesia & $137(48.6)$ & $\begin{array}{l}\text { Day care/Minor } \\
\text { Operating room }\end{array}$ & $97(32.3)$ \\
\hline Long anesthesia & $6(2.1)$ & Sonography suite & $11(3.7)$ \\
\hline Local anesthesia & & $\begin{array}{l}\text { Major Operating } \\
\text { room }\end{array}$ & $10(3.3)$ \\
\hline Other & $87(30.9)$ & Other & $24(7.8)$ \\
\hline
\end{tabular}

(79.1\% of respondents). Techniques to prevent postinjection steroid leakage and subcutaneous atrophy included: reinjecting lidocaine (14.18\%), quick withdrawal of needle (34.75\%), combination of the above two (10.64\%). 17\% respondents reported no specific preventive measures. Amongst those who selected "other", application of pressure, injecting normal saline, physiological serum, bupivacaine, air, limiting the volume injected, Z-track method and pressure application after needle withdrawal were reported.

\section{Post-procedure monitoring and instructions}

Most respondents indicated that they monitor the patient in the hospital until the effect of anesthesia wears off (77\%). A minority of respondents indicated full day or overnight observation (6.4 and $4.6 \%$, respectively).

\section{Age-related practices}

$47 \%$ respondents followed significantly different practices for children less than 5 years of age. Of these, the commonest age-dependent practice (72\%) was choice of anesthesia (Table 7).

Table 3 Ultrasound use for |AI

\begin{tabular}{llll}
$\begin{array}{l}\text { Use of ultrasound to guide IAI: } \mathbf{n}(\%) \\
\text { Total } \boldsymbol{n = 3 0 1}\end{array}$ & $\begin{array}{l}\text { Frequency of ultrasound } \\
\text { use in different joints } \\
\text { Total } \boldsymbol{n}=\mathbf{1 5 2}\end{array}$ \\
\hline Always & $22(7.3)$ & Hip & $152(100)$ \\
Selectively & $135(44.9)$ & Ankle & $137(90.1)$ \\
Never & $144(47.9)$ & Wrist & $101(66.5)$ \\
& & Shoulder & $63(41.5)$ \\
& & Small joints & $44(29)$ \\
\hline
\end{tabular}


Table 4 Therapeutic agent of choice for IAI

\begin{tabular}{ll}
\hline Agent of choice & Respondents N (\%) \\
\hline Triamcinolone Hexacetonide (TH) & $223(78.5)$ \\
Triamcinolone acetonide (TA) & $39(13.7)$ \\
Methylprednisolone & $10(3.5)$ \\
Hydrocortisone & $1(0.4)$ \\
Others $^{\mathrm{a}}$ & $11(3.9)$ \\
\hline
\end{tabular}

${ }^{\mathrm{a} O t h e r s: ~ B e t a m e t h a s o n e ~}$

\section{Associations}

Variations in practices based on geographical location of the respondents and years of training was analysed with chi-square and Fishers exact tests.

A statistically significant relationship was observed between use of local anaesthesia (LA) and geographical location of USA versus UK. None of the other practices, such as use of ultrasound, the setting of IAI, number of joints injected in one setting, or age-related practice variations varied significantly by geographical location. There was no significant difference in practices based on years of clinical experience. Physicians who had received formal training in IAI appeared to follow different practices in the less than 5-year age group, as compared to physicians without formal training (Table 8).

\section{Discussion}

The American College of Rheumatology (ACR) guidelines for management of JIA [3] recommend joint injections with glucocorticoids as an important modality of treatment for active arthritis, regardless of concurrent therapy. For oligoarthritis (involvement of 4 or fewer joints), intraarticular injections are recommended as initial treatment or after failing 2 months of treatment with NSAIDs.

In a survey about treatment of Oligoarticular JIA in North America, 90\% of physicians indicated use of IAI as either initial treatment or after failure of NSAIDs [8].

IAI in JIA is unequivocally recommended and widely used as the treatment of choice for active arthritis. However, to date, no recommendations regarding IAI practices have been published. In the recently published ACR guidelines of JIA, IAI receives a notable but small mention [9].

To the authors' knowledge, no studies have attempted to explore the variable practices related to IAIs in pediatrics. While some factors such as the setting of joint injection and number of joints injected did not show much variability, several other practice variations in IAI were observed in our study.

Most importantly, the choice of therapeutic agent remains a widely varying decision, based mostly on lack of availability of TH. Small prospective trials and retrospective chart reviews have studied the efficacy of TA and $\mathrm{TH}$ in IAI and concluded that $\mathrm{TH}$ offers an advantage to TA, due to a longer duration of action $[4,5]$. In a study by Eberhard et al. from New York, 794 IAIs were

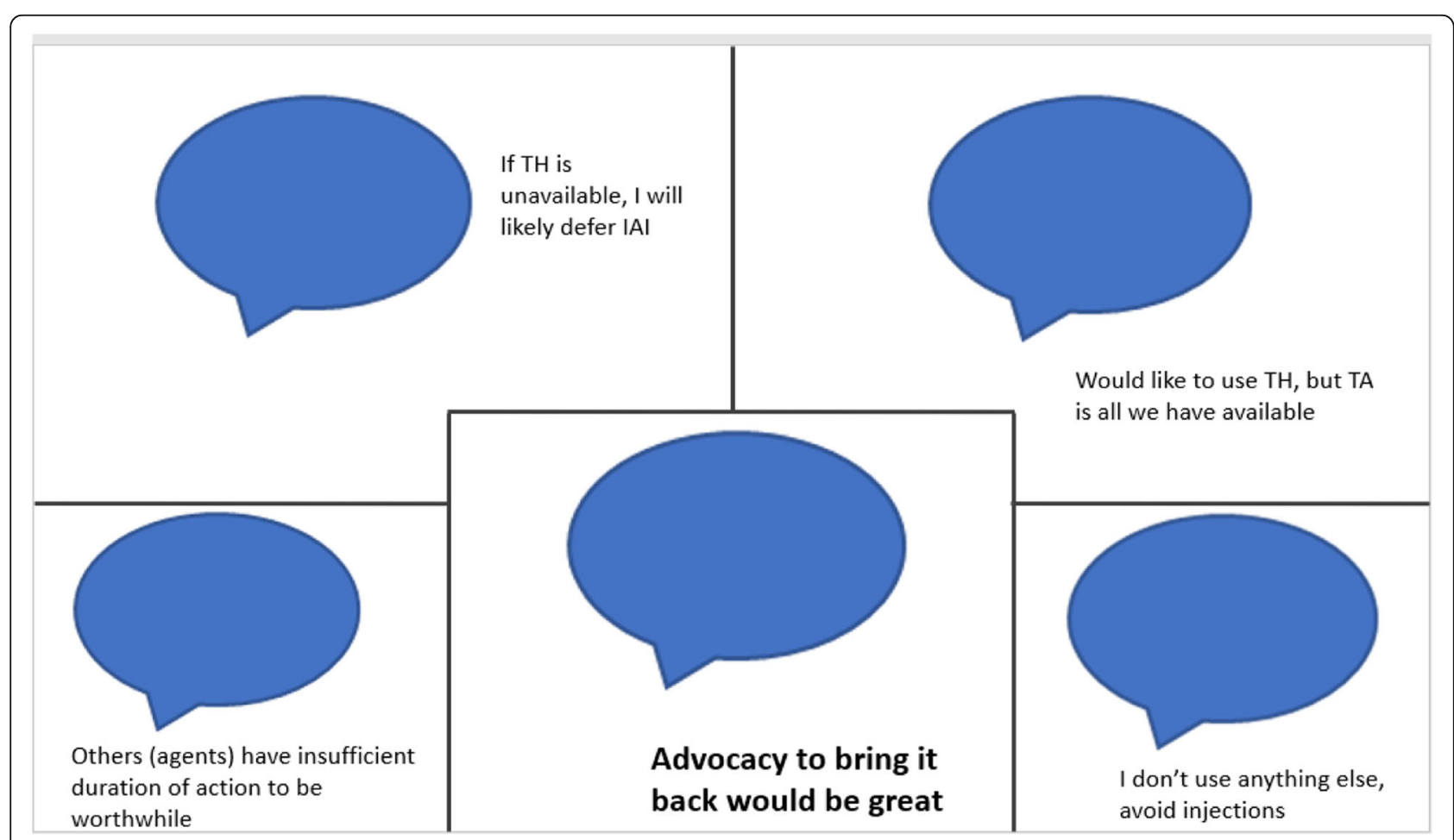

Fig. 2 Comments regarding TH non-availability 
Table 5 Dose of therapeutic agent

\begin{tabular}{lll}
\hline $\begin{array}{l}\text { Dose in TH } \\
\text { equivalent } \\
\text { (mg/kg) }\end{array}$ & \multicolumn{2}{l}{ Response frequency: $\mathbf{n}(\%)$} \\
\cline { 2 - 3 } & Large joints & Small joints \\
\hline 0.5 & $24(8.5)$ & $155(54.6)$ \\
1 & $180(63.4)$ & $36(12.7)$ \\
1.5 & $12(4.2)$ & 0 \\
2 & $29(10.2)$ & $1(0.4)$ \\
Other $^{\text {a }}$ & $39(13.7)$ & $50(17.6)$ \\
\hline
\end{tabular}

${ }^{\mathrm{a} O t h e r: ~ A b s o l u t e ~ d o s e s ~ r a n g i n g ~ f r o m ~} 10$ to $30 \mathrm{mg}$

examined of which 422 were injected with $\mathrm{TH}$ and 372 with TA. TH proved more effective than TA with respect to the time to relapse for first injection $(p<0.001)$ [10]. ACR guidelines for management of JIA also strongly recommend TH over TA for IAIs based on reports from observational studies and clinical experience of the voting members of the committee. However, as demonstrated in the results of our survey, more than half of the respondents indicated difficulty in obtaining $\mathrm{TH}$ and either resorted to an alternative agent or deferred the procedure entirely. $\mathrm{TH}$ shortage remains an ongoing issue in several parts of the world [7] and has been reported in the FDA list of current drug shortages [11]. Advocacy initiatives based on the success story of some local advocacy groups [12] should be initiated and pursued to fill this gap in availability of $\mathrm{TH}$.

Another major practice variation observed in this survey was use of ultrasound to guide joint injections. Almost half $(47.9 \%)$ respondents indicated not using ultrasound either routinely or even selectively for IAI. There is data indicating effectiveness of radiologically guided IAIs particularly for complex joints [13, 14]. In our survey, we did not explore the reasons for under utilization of ultrasound. The use of ultrasound to assess joint remission in JIA is also documented in the literature [15].

Table 6 Complications of IAI

\begin{tabular}{ll}
\hline Reported complication & $\begin{array}{l}\text { Total respondents: } \mathbf{N = \mathbf { 2 8 2 }} \\
\mathbf{N}(\%)\end{array}$ \\
\hline Subcutaneous atrophy (drug leakage) & $223(79.1)$ \\
Fat necrosis & $56(19.9)$ \\
Local bleeding & $39(13.8)$ \\
Anesthetic complications & $14(5)$ \\
latrogenic infections & $7(2.5)$ \\
Tendon rupture & $3(1.1)$ \\
Hypopigmentation (without atrophy) & $4(<1)$ \\
Periarticular calcifications & $3(<1)$ \\
Pain & $6(<1)$ \\
Seizures & $1(<1)$ \\
No complications & $51(18.1)$ \\
\hline
\end{tabular}

Table 7 Age dependent practice variations

\begin{tabular}{ll}
\hline $\begin{array}{l}\text { Modified age-related practice for } \\
\text { children }<\mathbf{5} \text { years }\end{array}$ & $\begin{array}{l}\text { Frequency: } \mathbf{n}(\%) \\
\text { Total } \boldsymbol{n}=\mathbf{1 3 1}\end{array}$ \\
\hline $\begin{array}{l}\text { Use of ultrasound guidance } \\
\text { Choice of anesthesia }\end{array}$ & $31(23.7)$ \\
$\begin{array}{l}\text { Choice of setting for procedure } \\
\text { (inpatient versus procedure room) }\end{array}$ & $94(71.8)$ \\
Number of joints injected & $68(51.9)$ \\
Duration of monitoring & $36(27.5)$ \\
Other (please specify) & $22(16.8)$ \\
\hline
\end{tabular}

IAI is a relatively safe procedure without major systemic side effects. The incidence of reported complications ranges from 2.6 to $8.3 \%$ [16, 17]. Some known minor complications of IAI include infections, skin atrophy, hypopigmentation, articular calcifications, and avascular necrosis [18].

Notably, $18 \%$ of our respondents had not witnessed a single complication following IAI.

The optimal time for post-procedure rest is controversial. In our study, only a minority of respondents observed the patient overnight or for $24 \mathrm{~h}$. Although we did not specifically ask regarding resting or splinting an individual joint, the period of observation indirectly implies resting the patient (hence joint). A Cochrane review to determine the effects of rest following IAI in adults or children with arthritis concluded that there is some evidence for resting knees following IAI in adults, the findings must be extrapolated with caution in children with JIA [19].

\section{Limitations of the study}

Surveys have an inherent limitation of differences in understanding and interpreting questions. Most questions in the survey were self-explanatory, however given the multilingual nature of the global respondents, there was an inherent risk of differences in understanding and interpreting questions. Although $42 \%$ (the number of respondents that use IAI routinely) would be considered a satisfactory response rate, there the rest that likely use IAIs in their practice but whose response could not be

Table 8 Results of Chi-square and Fisher exact test

\begin{tabular}{|c|c|c|c|c|}
\hline & \multicolumn{2}{|c|}{ Frequency (\%) } & \multirow{2}{*}{$\begin{array}{l}\begin{array}{l}\text { Chi- } \\
\text { square } \\
\text { value }\end{array} \\
5.681\end{array}$} & \multirow{2}{*}{$\begin{array}{l}p \text {-value } \\
0.017\end{array}$} \\
\hline LA use & USA: 49/65 & UK: 10/21 & & \\
\hline & 47 & 75 & & \\
\hline \multirow[t]{2}{*}{$\begin{array}{l}\text { Variation in } \\
\text { practices for age }< \\
5 \text { years }\end{array}$} & $\begin{array}{l}\text { Formal } \\
\text { training in } \\
\mid \mathrm{Al}\end{array}$ & $\begin{array}{l}\text { No formal } \\
\text { training in } \\
\text { IAI }\end{array}$ & - & \multirow{2}{*}{$\begin{array}{l}< \\
\mathbf{0 . 0 0 0 0 1} \\
\text { (Fisher } \\
\text { exact } \\
\text { test) }\end{array}$} \\
\hline & 67 & 0 & & \\
\hline
\end{tabular}

LA Local Anesthesia 
elicited as they could not be reached through this survey. It was beyond the scope of this study to explore the clinical and cost implications of these variations.

\section{Conclusions}

IAI is a common modality of treatment in JIA but does not have established practice standards. Major variations were noted in the choice of therapeutic agent and use of ultrasound to guide IAIs in this study. Differing practices in a younger age group of patients was found to be significantly associated with the presence or absence of physicians' formal training in IAI. Use of LA was significantly less frequent in some geographical areas, which may be explained by institutional or patient preferences, but needs to be further explored. The variations observed in this study beg for a worldwide collaboration to determine best practices and recommendations for this efficacious and safe procedure.

\section{Future directions}

Further studies are needed to determine efficacious and cost-effective procedural practices for joint injections. The authors strongly recommend the development of a working group dedicated to developing a consensus statement on this extremely common, safe, and efficacious procedure in pediatric rheumatology. With COVID time teaching us the power of online collaboration this could be a relatively inexpensive exercise. Another important issue highlighted in this study, which may be within the realm of advocacy group agendas, is addressing the non-availability of $\mathrm{TH}$ in several parts of the world.

\section{Abbreviations \\ IAl: Intra-articular Injection; JA: Juvenile Idiopathic Arthritis; PRINTO: Pediatric Rheumatology International Trials Organization; PRCSG: Pediatric Rheumatology Collaborative Study Group; ACR: American College of Rheumatology; TH: Triamcinolone Hexacetonide; TA: Triamcinolone Acetonide; NSAIDs: Non-Steroidal Anti-inflammatory Drugs; CARRA: Childhood Arthritis \& Rheumatology Research Alliance; LA: Local Anesthesia}

\section{Acknowledgements}

The Authors wish to acknowledge:

Pediatric Rheumatology Collaborative Study Group (PRCSG) and Dr. Hermine Brunner.

Pediatric Rheumatology International Trials Organization (PRINTO) and Dr. Marco Garrone for help with disseminating the survey

And

Ethics committee of Jaslok Hospital and Research Center, Mumbai, India for approving this study.

\section{Authors' contributions}

RPK: Conception of idea, data gathering, revisions in manuscript. AD: Designing the survey, data gathering, data analysis, manuscript drafting and revisions. The authors' read and approved the final manuscript.

\section{Funding}

None.

\section{Availability of data and materials}

The datasets used and/or analysed during the current study are available from the corresponding author on reasonable request.

\section{Ethics approval and consent to participate}

Ethics approval was obtained from Ethics Committee of Jaslok Hospital and Research Center, Mumbai.

\section{Consent for publication}

NA.

\section{Competing interests}

The authors declare that they have no competing interests.

\section{Author details}

${ }^{1}$ Hospital for Sick Children, 8253, Burton Wing, 555 University Avenue, Toronto, ON M5G 1X8, Canada. ${ }^{2}$ Pediatric Rheumatology, SRCC Children's Hospital, 1-1A, Keshavrao Khadye Marg, Haji Ali, Haji Ali Government Colony, Mahalakshmi, Mumbai, Maharashtra 400034, India.

Received: 11 February 2020 Accepted: 6 October 2020

Published online: 17 October 2020

\section{References}

1. Allen RC, Gross KR, Laxer RM, et al. Intraarticular triamcinolone hexacetonide in the management of chronic arthritis in children. Arthritis Rheum. 1986; 29(8):997-1001.

2. Ansell BM. Rheumatic disorders of childhood. London: Butterworth's; 1980. p. 144.

3. Beukelman R, Patkar N, Saag K. American College of Rheumatology recommendations for the treatment of juvenile idiopathic arthritis: initiation and safety monitoring of therapeutic agents for the treatment of arthritis and systemic features. Arthritis Care Res. 2011;63(4):465-82.

4. Zulian F, et al. Comparison of intra-articular triamcinolone hexacetonide and triamcinolone acetonide in oligoarticular juvenile idiopathic arthritis. Rheumatology (Oxford, England). 2003;42(10):1254-9. https://doi.org/10. 1093/rheumatology/keg358.

5. Zulian F, et al. Triamcinolone acetonide and hexacetonide intra-articular treatment of symmetrical joints in juvenile idiopathic arthritis: a doubleblind trial. Rheumatology (Oxford, England). 2004;43(10):1288-91. https://doi. org/10.1093/rheumatology/keh313.

6. Garg N, et al. Intra-articular and soft tissue injections, a systematic review of relative efficacy of various corticosteroids. Clin Rheumatol. 2014;33(12):1695706. https://doi.org/10.1007/s10067-014-2572-8.

7. Bingham CA, Scalzi L, Boomsma D, Groh B, Gaffney N, Sertial S, Hahn T, Lacroce V, Ostrov B. Resurrecting Triamcinolone Hexacetonide (the Steroid Formerly Known as Aristospan ${ }^{\oplus}$ ): Efficacy and Safety of a Compounded Preparation of Triamcinolone Hexacetonide for Intra-Articular Injection in Children with Arthritis [abstract]. Arthritis Rheumatol. 2018;70(suppl 10). https://acrabstracts.org/abstract/resurrecting-triamcinolone-hexacetonidethe-steroid-formerly-known-as-aristospan-efficacy-and-safety-ofacompounded-preparation-of-triamcinolone-hexacetonide-for-intra-articularinjection-in/. Accessed 11 Oct 2020.

8. Beukelman T, Guevara J, Albert D, et al. Variation in the initial treatment of knee monoarthritis in juvenile idiopathic arthritis: a survey of pediatric rheumatologists in the United States and Canada. J Rheumatol. 2007;34:1918-24.

9. Ringold S, et al. 2019 American College of Rheumatology/Arthritis Foundation guideline for the treatment of juvenile idiopathic arthritis: therapeutic approaches for non-systemic polyarthritis, sacroiliitis, and enthesitis. Arthritis Care Res. 2019;71(6):717-34. https://doi.org/10.1002/acr.23870.

10. Eberhard BA, Sison MC, Gottlieb BS, llowite NT. Comparison of the intraarticular effectiveness of triamcinolone hexacetonide and triamcinolone acetonide in treatment of juvenile rheumatoid arthritis. J Rheumatol. 2004; 31(12):2507 LP-2512.

11. Current and Resolved Drug Shortages and Discontinuations Reported to FDA. FDA drug shortages. U. S Food and Drug administration. https://www. accessdata.fda.gov/scripts/drugshortages/dsp_ActivelngredientDetails. cfm?Al=Triamcinolone\%20Hexacetonide\%20Injectable $\% 20$ Suspension $\% 2$ O(Aristospan)\&st=c.

12. Medexus reports Triamcinolone Hexacetonide injectable suspension approved for public reimbursement in Canada. Medexus Pharmaceuticals Inc. April 8, 2020 in GlobeNewswire. https://www.globenewswire.com/news- 
release/2020/04/08/2013564/0/en/Medexus-Reports-TriamcinoloneHexacetonide-Injectable-Suspension-Approved-for-Public-Reimbursement-inCanada.html.

13. Young $\mathrm{CM}$, et al. Ultrasound-guided corticosteroid injection therapy for juvenile idiopathic arthritis: 12-year care experience. Pediatr Radiol. 2012; 42(12):1481-9. https://doi.org/10.1007/s00247-012-2487-y.

14. Cahill AM, et al. Benefit of fluoroscopically guided intraarticular, long-acting corticosteroid injection for subtalar arthritis in juvenile idiopathic arthritis. Pediatr Radiol. 2007;37(6):544-8. https://doi.org/10.1007/s00247-007-0457-6.

15. Chhabra A, et al. Real-world effectiveness of common treatment strategies for juvenile idiopathic arthritis: results from a Canadian cohort. Arthritis Care Res. 2019. https://doi.org/10.1002/acr.23922.

16. Job-Deslandre C, Menkes CJ. Complications of intra-articular injections of triamcinolone hexacetonide in chronic arthritis in children. Clin Exp Rheumatol. 1990:8(4):413-6.

17. Cleary AG, Murphy HD, Davidson JE. Intra-articular corticosteroid injections in juvenile idiopathic arthritis. Arch Dis Childhood. 2003;88:192-6.

18. Breit W, Frosch M, Meyer U, Heinecke A, Ganser G. A subgroup-specific evaluation of the efficacy of intraarticular triamcinolone hexacetonide in juvenile chronic arthritis. J Rheumatol. 2000;27(11):2696-702.

19. Wallen MM, Gillies D. Intra-articular steroids and splints/rest for children with juvenile idiopathic arthritis and adults with rheumatoid arthritis. Cochrane Database Syst Rev 2006, Issue 1. Art. No.: CD002824. DOI: https://doi.org/10. 1002/14651858.CD002824.pub2.

\section{Publisher's Note}

Springer Nature remains neutral with regard to jurisdictional claims in published maps and institutional affiliations.

Ready to submit your research? Choose BMC and benefit from:

- fast, convenient online submission

- thorough peer review by experienced researchers in your field

- rapid publication on acceptance

- support for research data, including large and complex data types

- gold Open Access which fosters wider collaboration and increased citations

- maximum visibility for your research: over $100 \mathrm{M}$ website views per year

At BMC, research is always in progress.

Learn more biomedcentral.com/submissions 